\title{
Polynomial modelling of CHAMP satellite data to investigate rapid secular variation fluctuations over southern Africa during 2003 and 2004
}

\author{
E. Nahayo and P. B. Kotzé
}

South African National Space Agency (SANSA) Space Science, PO Box 32, Hermanus, South Africa

(Received March 25, 2010; Revised February 23, 2012; Accepted March 6, 2012; Online published August 16, 2012)

\begin{abstract}
Polynomial surface modelling is one of several useful methods to represent the geomagnetic field over a restricted area. This technique was applied to CHAMP satellite data for the period 2001-2005 to investigate rapid secular variation fluctuations at $400 \mathrm{~km}$ altitude over southern Africa region between $10^{\circ}$ and $40^{\circ}$ South in latitude and between $10^{\circ}$ and $40^{\circ}$ East in longitude. The results are compared with an analysis of monthly time series data of 2 magnetic observatories in the region, namely, Hermanus (HER) in South Africa and Tsumeb (TSU) in Namibia. Consequently 2 rapid secular variation fluctuations are identified around 2003.0 and 2004.0 respectively.
\end{abstract}

Key words: Satellite and ground data analysis, regional field modelling, rapid secular variation fluctuations.

\section{Introduction}

The Earth's main magnetic field, generated by a selfsustaining dynamo in the liquid outer core, is not constant but changes with time. This phenomenon is known as secular variation (SV), while abrupt changes in the linear secular variation trend are known as geomagnetic jerks or secular variation impulses (Malin and Hodder, 1982; Courtillot and LeMouël, 1984; Mandea et al., 2000). The torsional oscillations in the fluid outer core have been used to explain the occurrence of geomagnetic jerks (Bloxham et al., 2002) on a decadal timescale. No direct information, however is available for timescales of less than a couple of years (Mandea and Olsen, 2009). It has been shown that changes in the magnetic field occurring over only few months, as well as the fluid flow at the top of the core that is believed to generate them, can be resolved (Olsen and Mandea, 2008). These changes involving rapid variations over timescale of few months have been called recently rapid secular variation fluctuations, or, in short, rapid fluctuations by Mandea and Olsen (2009). However, the filtering effect of the electrical conducting mantle in masking short-period variations of the geomagnetic field is still unclear due to the uncertainty on the value of mantle electrical conductivity. Secular change of the Earth's magnetic field is a comparatively regional phenomenon that does not proceed in a regular manner across the Earth. This gives rise to regions where the magnetic field changes more rapidly than elsewhere, like for instance southern Africa (Korte et al., 2007). Several investigations using time series of geomagnetic data from worldwide magnetic observatories and satellite data have indeed revealed rapid secular variation fluctuations (Olsen and Mandea, 2007).

Copyright (C) The Society of Geomagnetism and Earth, Planetary and Space Sciences (SGEPSS); The Seismological Society of Japan; The Volcanological Society of Japan; The Geodetic Society of Japan; The Japanese Society for Planetary Sciences; TERRAPUB.

doi:10.5047/eps.2012.03.001
This paper discusses the occurrence of rapid secular variation fluctuations around 2003.0 and 2004.0 over southern Africa. This investigation was done by modelling CHAMP vector magnetic field measurements over southern Africa by means of surface polynomial technique, using quiet time data ( $D_{\text {st }}$ less than $\pm 20 \mathrm{nT}$ ) between 2001 and 2005. Significant current systems exist within and on the boundary of the magnetosphere, resulting in large magnetic fields described by various magnetic activity indices. For this investigation however, we assume that ring current dominates at the mid-latitudes considered and that this can be represented by the $D_{\text {st }}$ index (Kotzé, 2001).

The results of this investigation are supported by the analysis of the monthly time series data for the ground observatories HER (in South Africa) and TSU (in Namibia).

\section{Method and Analytical Techniques}

The following surface polynomial was used:

$$
B(\varphi, \lambda)=\sum_{n=0}^{N} \sum_{m=0}^{N} k_{m n} \times\left(\varphi-\varphi_{0}\right)^{n} \times\left(\lambda-\lambda_{0}\right)^{m}
$$

where $B$ is the magnitude of the main field for each element (north component $X$, east component $Y$, and vertical component $Z$ ) at the point with geographic coordinates $\varphi$ (latitude) and $\lambda$ (longitude), $k_{m n}$ is a numerical coefficient and $\varphi_{0}$ and $\lambda_{0}$ are the coordinates of the center of the modelled area: $\varphi_{0}=25^{\circ} \mathrm{S}$ and $\lambda_{0}=25^{\circ} \mathrm{E}$. The degree of the polynomial is determined by the value of integer $N$ $(N=1,2,3,4,5, \ldots)$.

By assuming that $B(\varphi, \lambda)$ is the measured magnitude of the main field element or a secular variation value at a given point of latitude $\varphi$ and longitude $\lambda$, and $k_{m n}$ is unknown, a redefined system of conditional equations is obtained and solved by the least squares method. One of the characteristics of this surface polynomial is that when the truncation degree is increased, $k_{m n}$ coefficients converge 
Table 1. The RMS misfit errors between the measured satellite data and data obtained from the main field models (January 2002), and RMS differences between the SV data and data obtained from SV models (January-December, 2002) at $400 \mathrm{~km}$ altitude.

\begin{tabular}{cccc|ccc}
\hline $\begin{array}{c}\text { Polynomial } \\
\text { degree }\end{array}$ & $\begin{array}{c}X \\
(\mathrm{nT})\end{array}$ & $\begin{array}{c}\text { Main field } \\
(\mathrm{nT})\end{array}$ & $\begin{array}{c}Z \\
(\mathrm{nT})\end{array}$ & $\begin{array}{c}\mathrm{SV} / d t \\
(\mathrm{nT} / \text { year })\end{array}$ & $\begin{array}{c}d Y / d t \\
(\mathrm{nT} / \text { year })\end{array}$ & $\begin{array}{c}d Z / d t \\
(\mathrm{nT} / \text { year })\end{array}$ \\
\hline 2 & 71.6 & 38.8 & 252.8 & 4.1 & 6.9 & 3.7 \\
3 & 40.6 & 26.3 & 20.8 & 3.4 & 6.1 & 2.9 \\
4 & 8.7 & 5.4 & 12.5 & 2.9 & & 2.0 \\
5 & 7.8 & 5.1 & 3.4 & & & \\
6 & 7.4 & 4.8 & 3.3 & & & \\
\hline
\end{tabular}

Table 2. The mean values and standard deviations from the mean of RMS misfit errors between the measured satellite data and $5^{\text {th }}$ degree polynomial main field models (January and December), and RMS differences between the SV data (January-December) and data obtained from the $2^{\text {nd }}$ degree polynomial SV models for years 2001-2005.

\begin{tabular}{cccc|ccc}
\hline & \multicolumn{3}{c|}{ Main field } & \multicolumn{3}{c}{$\mathrm{SV}$} \\
& $X$ & $Y$ & $Z$ & $d X / d t$ & $d Y / d t$ & $d Z / d t$ \\
& $(\mathrm{nT})$ & $(\mathrm{nT})$ & $(\mathrm{nT})$ & $(\mathrm{nT} /$ year) & $\begin{array}{c}d \mathrm{nT} / \text { year }) \\
(\mathrm{nT} / \text { year })\end{array}$ \\
\hline Mean values of RMS misfit errors & 8.6 & 6.2 & 4.3 & 6.4 & 5.0 & 3.5 \\
Standard deviations & 2.0 & 1.7 & 1.2 & 1.6 & 1.7 & 1.1 \\
\hline
\end{tabular}

to zero.

Without any altitude dependence the polynomial modelling technique requires that data are reduced to the same altitude (400 km, the mean CHAMP altitude). This was achieved using the IGRF 10 model (Maus et al., 2005). For a data point value $\mathrm{D}$ at a given geodetic coordinate $(\varphi, \lambda, S)$, the data point value at a new altitude $N$ is given as follows:

$$
\mathrm{D}_{(\varphi, \lambda, N)}=\mathrm{D}_{(\varphi, \lambda, S)}+\left(\operatorname{IGRF} 10_{(\varphi, \lambda, N)}-\operatorname{IGRF} 10_{(\varphi, \lambda, S)}\right)
$$

where $S$ is the satellite altitude.

A comparative evaluation of RMS (Root-Mean-Square) differences between observations and model values is reported in Table 1 and shows that the $5^{\text {th }}$ and $6^{\text {th }}$ degree polynomials could be considered for main field modelling (the difference in their RMS misfit errors in the $X, Y$ and $Z$ components is less than $0.5 \mathrm{nT}$ ) and that the $2^{\text {nd }}, 3^{\text {rd }}$ and $4^{\text {th }}$ degree polynomials for secular variation models (the difference in their RMS misfit errors in the $X$ and $Y$ components is less than $1.5 \mathrm{nT}$, while for the $Z$-component it is less than $2 \mathrm{nT}$ ). Since the main aim is to study the temporal change of the core field characterised by the long wavelength, the trade-off was made between the minimum RMS misfit error and the lowest degree that would be suitable to study the core field temporal change. In addition, the high degree polynomials increase the edge effects, reducing the region of validity of the modelled area (Ardizone and Herraiz, 2000). Therefore, a $5^{\text {th }}$ degree polynomial was the best choice for main field modelling, while a $2^{\text {nd }}$ degree polynomial was best suited to derive secular variation field models.

The statistical analysis of the values of RMS misfit errors between the measured satellite data and the main field polynomial models and between the SV data and the SV polynomial models for the period 2001-2005 are presented in Table 2. Large RMS misfit errors were observed in December for 2001, 2002 and 2003, with main field $X$ component values of $11.3 \mathrm{nT}, 11.6 \mathrm{nT}$ and $11.5 \mathrm{nT}$ respectively.

In the present analysis of satellite data, 2 methods were

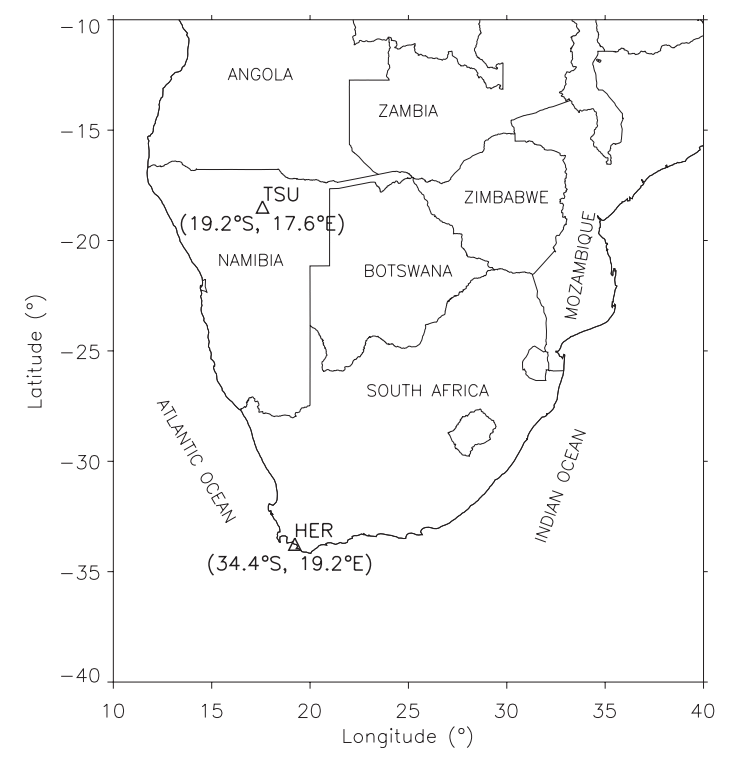

Fig. 1. The map showing the 2 selected points at $400 \mathrm{~km}$ just above 2 permanent observatories (HER and TSU).

used:

(a) The derivation of an annual secular variation field model for each component in order to monitor the evolution of the secular variation contour lines.

(b) The second approach was to select 2 reference points at $400 \mathrm{~km}$ altitude (the mean CHAMP altitude) just above HER and TSU as shown in Fig. 1. The selected 2 points are situated few degrees of latitude and longitude away from the boundary of the region of interest in order to limit errors in our data. As reported by Shu et al. (1996), Pochtarev (1984) showed that for any two-dimensional model of a limited area, the approximation error increases toward the boundary of this area. Another reason of selecting reference points (just above HER and TSU) is to enable us to compare 

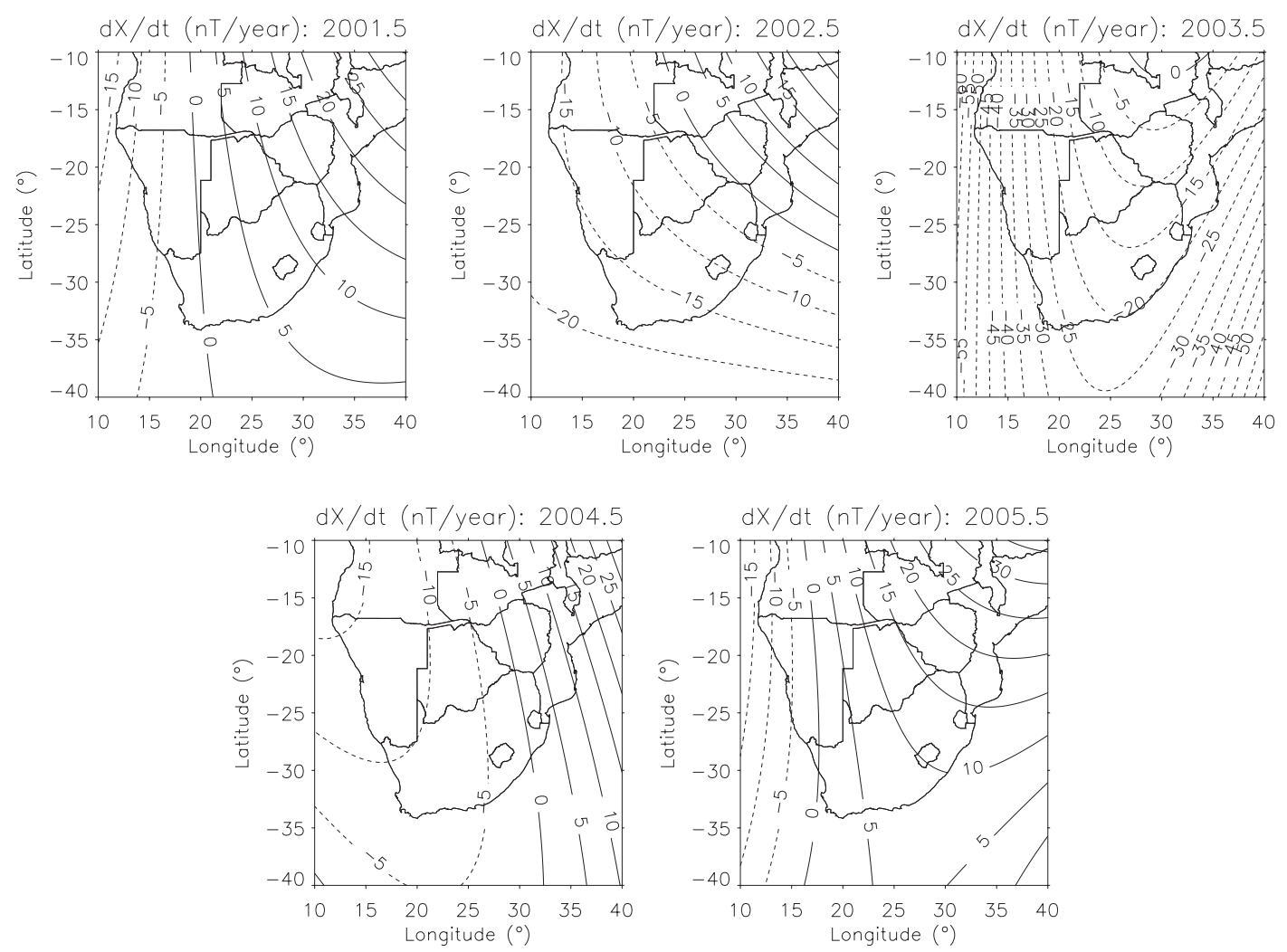

Fig. 2. The maps showing the first time derivative of the north component $X$ at $400 \mathrm{~km}$ altitude for years $2001-2005$ derived from PolyM model.
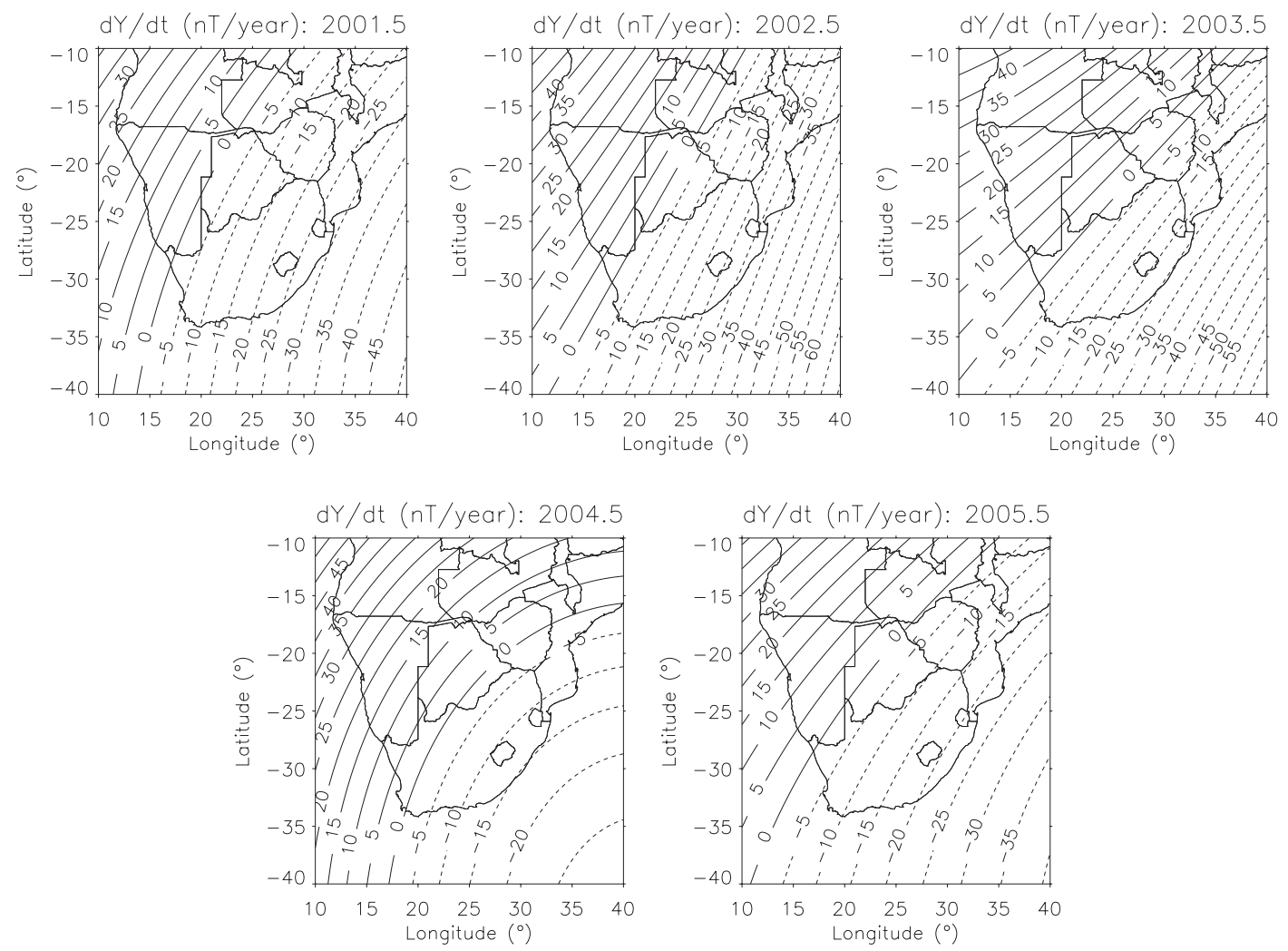

Fig. 3. The maps showing the first time derivative of the east component $Y$ at $400 \mathrm{~km}$ altitude for years $2001-2005$ derived from PolyM model. 

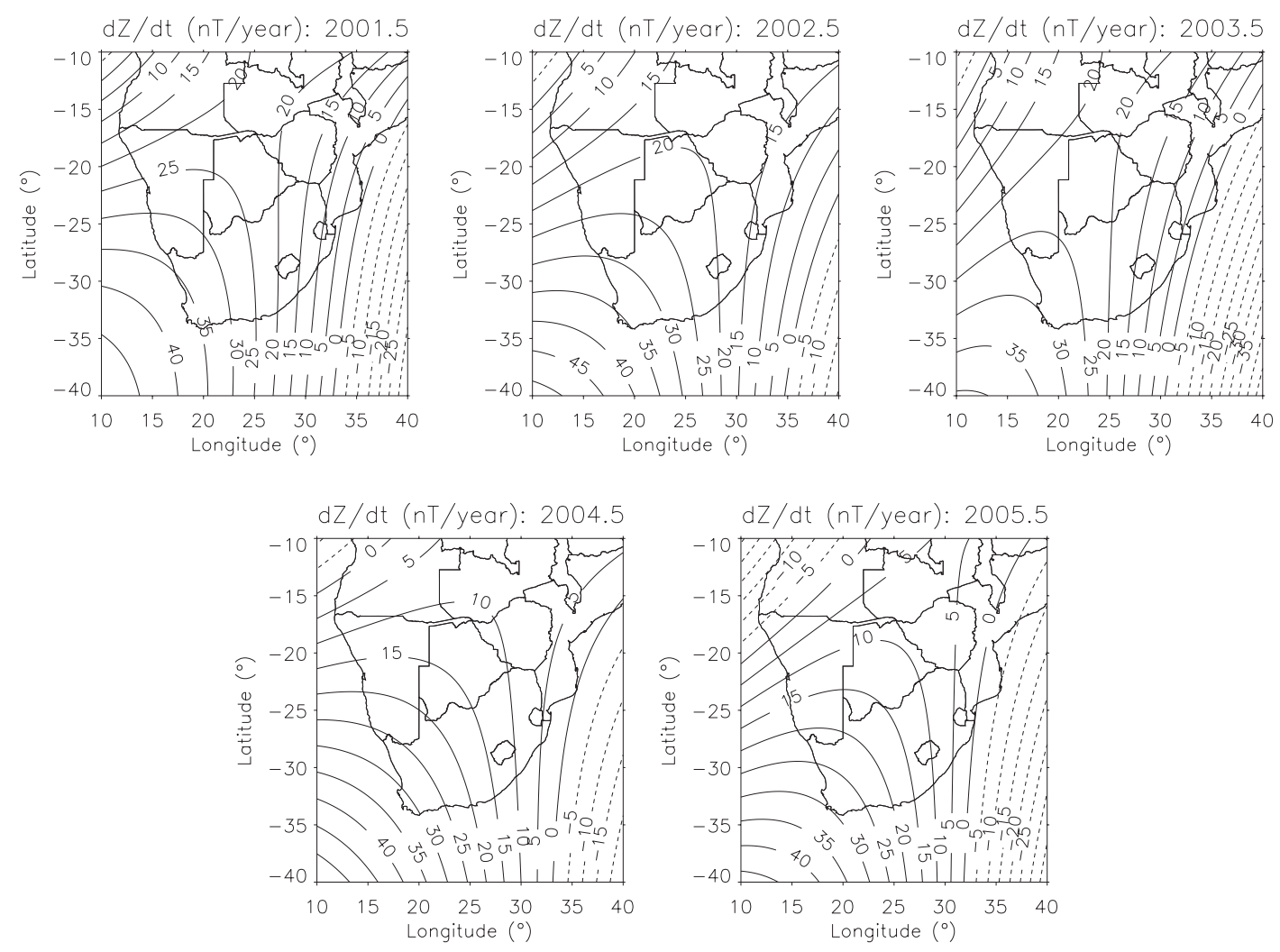

Fig. 4. The maps showing the first time derivative of the vertical component $Z$ at $400 \mathrm{~km}$ altitude for years $2001-2005$ derived from PolyM model.
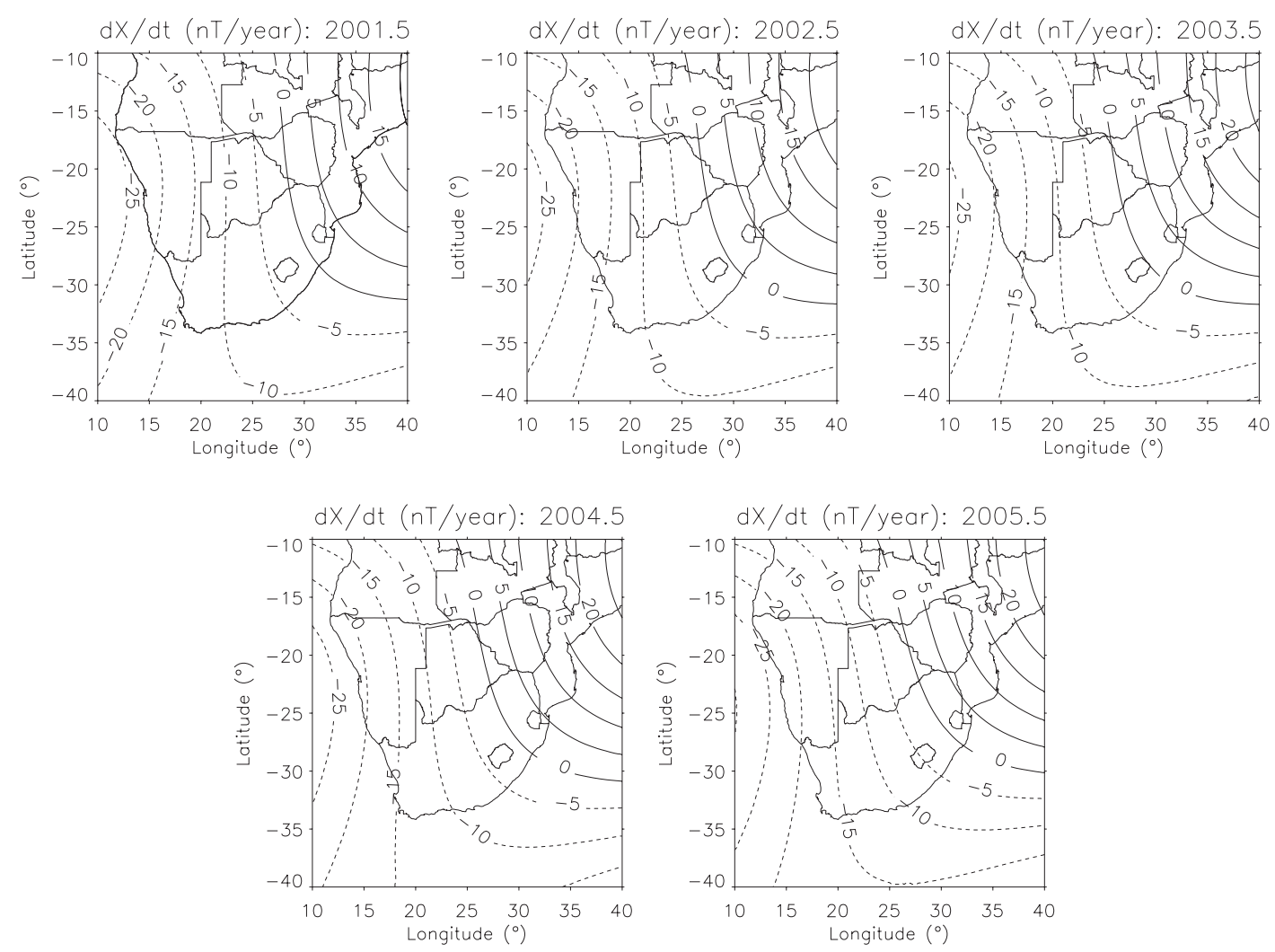

Fig. 5. The maps showing the first time derivative of the north component $X$ at $400 \mathrm{~km}$ altitude for years 2001-2005 derived from CHAOS-2 model. 

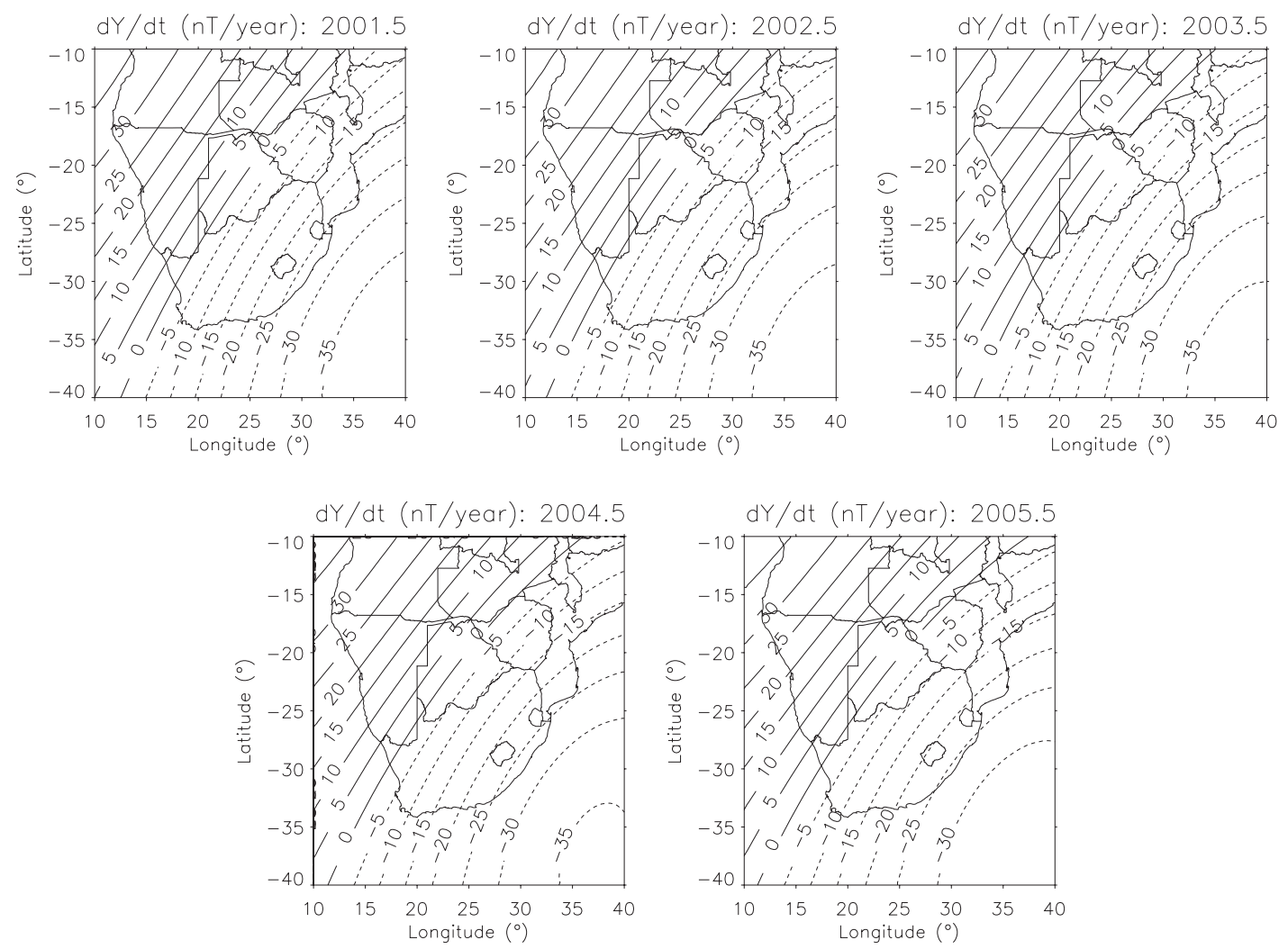

Fig. 6. The maps showing the first time derivative of the east component $Y$ at $400 \mathrm{~km}$ altitude for years 2001-2005 derived from CHAOS-2 model.
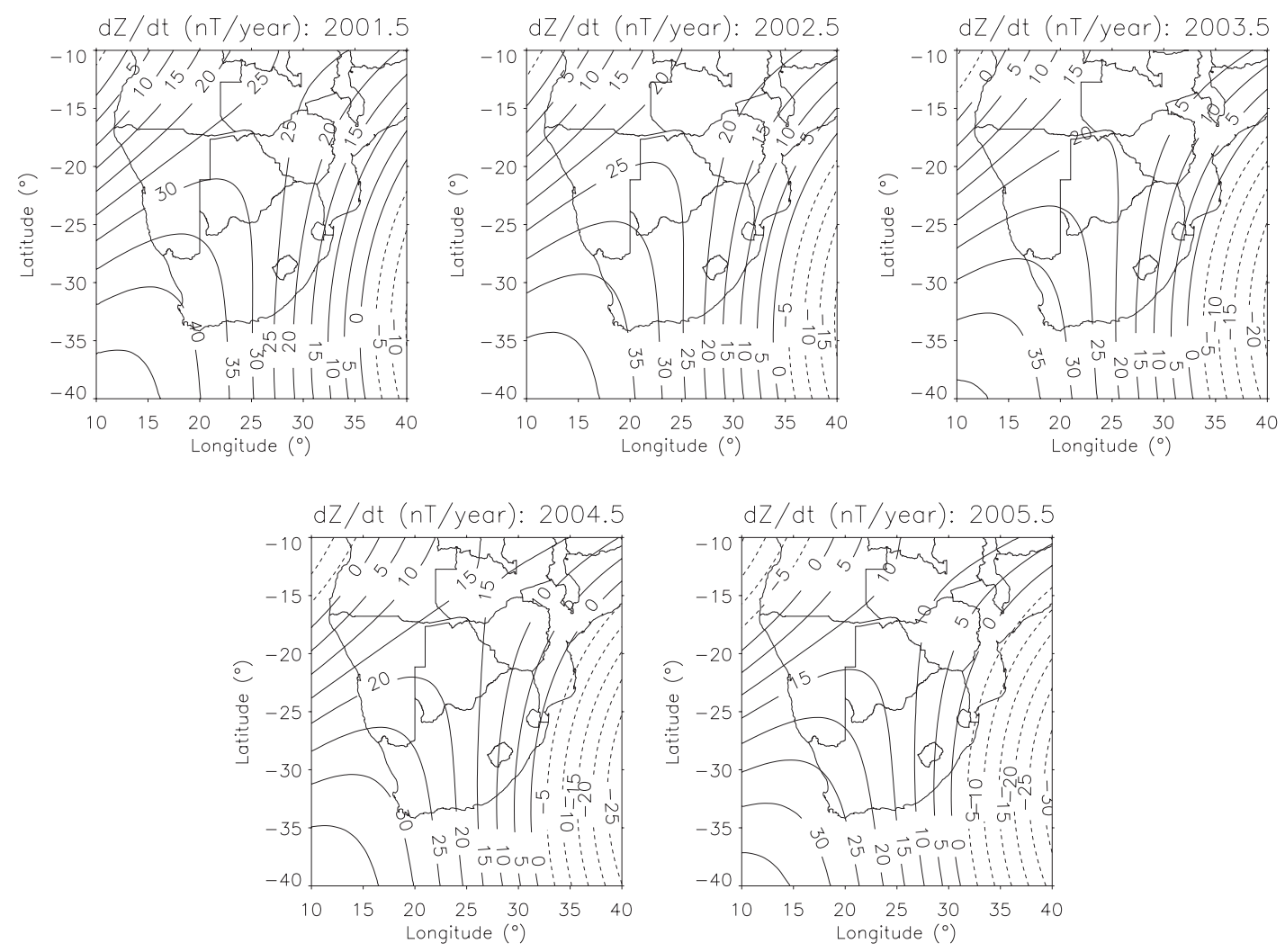

Fig. 7. The maps showing the first time derivative of the vertical component $Z$ at $400 \mathrm{~km}$ altitude for years 2001-2005 derived from CHAOS-2 model. 

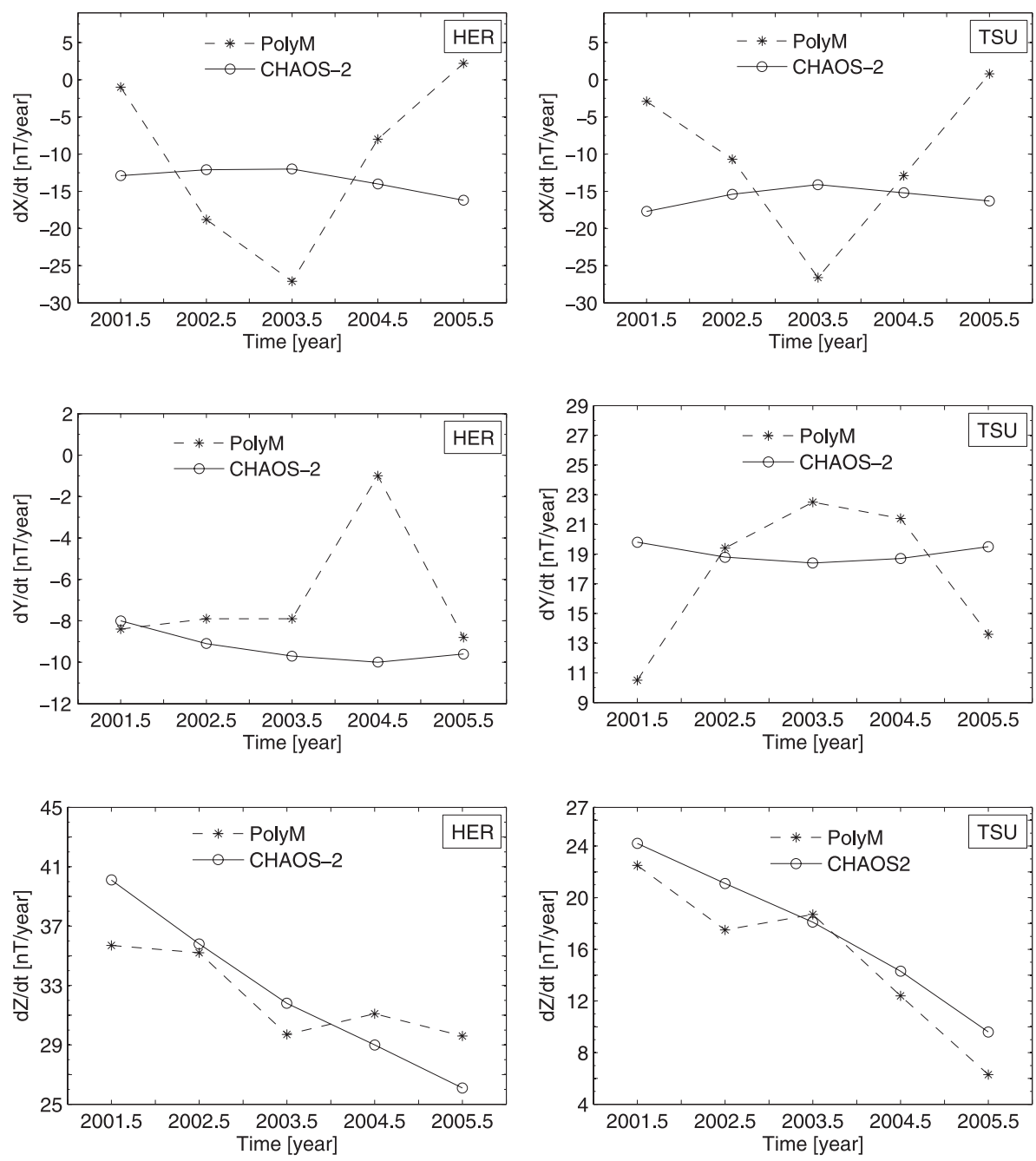

Fig. 8. The plots of the comparison of PolyM with CHAOS-2 at two selected points (at $400 \mathrm{~km}$ altitude just above HER and TSU) for years 2001-2005. The annual secular variation in $X, Y$ and $Z$ components were calculated using the monthly main field models of January and December based on CHAMP satellite data at $400 \mathrm{~km}$ altitude.

the results at reference points with the results of the ground-based observatory data analysis. The monthly main field polynomial models, the main field polynomial models generated for every month using only the night and quiet time satellite data recorded in this month, were used to compute monthly values at corresponding points for years 2001-2005.

Secular variation values for each of $X, Y$ and $Z$ components in the method (b) and in the analysis of ground data at 2 permanent observatories (HER and TSU) were calculated as follow:

$$
\begin{aligned}
d B / d t & =\dot{B}(t) \\
& =[B(t+6)-B(t-6)] / 1 \text { year }(B=X, Y \text { or } Z),
\end{aligned}
$$

where the unit of $t$ is month. In order to remove the annual variation, caused by magnetospheric and ionospheric currents and their Earth-induced counterparts, a 12-month running mean was applied to $\dot{B}(t)(B=X, Y$ or $Z)$ (Olsen and Mandea, 2007).

\section{Data: Source and Selection}

The German small satellite CHAMP was launched on July 15, 2000 into a circular, near polar and $454 \mathrm{~km}$ altitude orbit. The design of the fluxgate magnetometer on board is based on a compact spherical coil sensor, developed and manufactured by the Technical University of Denmark in Lyngby. The characteristics of the fluxgate magnetometer include the coverage of the full $\pm 65000 \mathrm{nT}$ range of the Earth's field in $X, Y$ and $Z$ components. The overall noise level is of the order of $50 \mathrm{pT}$ (RMS). In nominal operation mode the field vector is sampled at a rate of $50 \mathrm{~Hz}$ providing a spatial resolution along the orbit of approximately $150 \mathrm{~m}$ (Lühr, 2001).

The data selection was done on the CHAMP vector magnetic field measurements for years 2001-2005 that cover the southern Africa region, the area between $10^{\circ}$ and $40^{\circ}$ South in latitude and $10^{\circ}$ and $40^{\circ}$ East in longitude. In particular only quiet time data corresponding to a $D_{\text {st }}$ index between $-20 \mathrm{nT}$ and $+20 \mathrm{nT}$ measured during the universal time intervals 16:00-24:00 and 00:00-05:00 were considered for generating the contour maps in the method (a) and for the study of the secular variation at 2 selected points in 

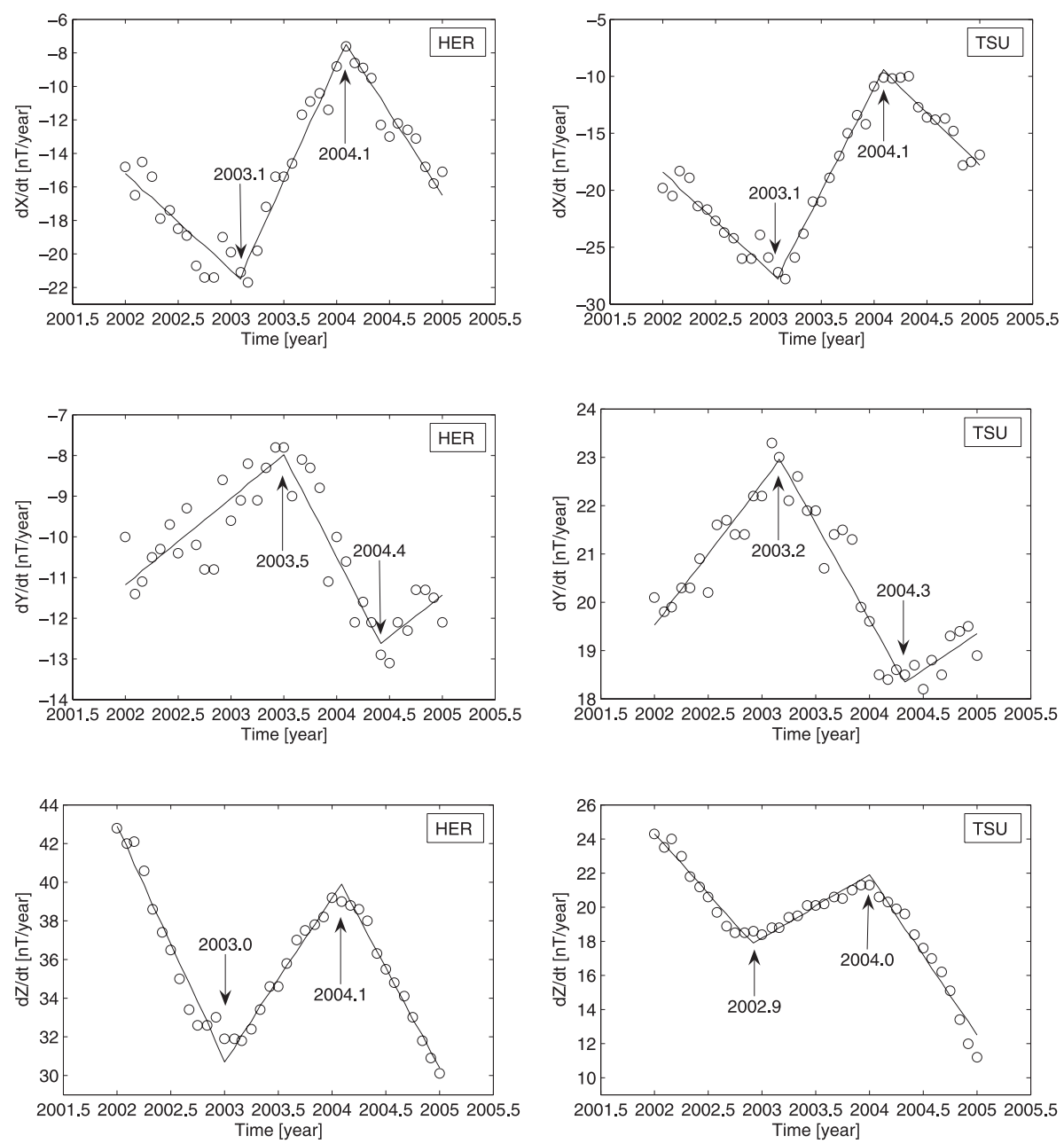

Fig. 9. The plots of the first time derivative of 3 components $(d X / d t, d Y / d t$, and $d Z / d t)$ at the selected points for years 2001-2005. The indicated epochs of rapid SV fluctuations are associated with an error of \pm 0.3 year. The monthly mean values were generated using the monthly main field data from polynomial modelling of satellite data at $400 \mathrm{~km}$ altitude.

the method (b). The choice of the time interval for data selection was done not to use satellite data that were contaminated by the solar quiet day variation. The geomagnetic field has a regular variation with a fundamental period of 24 hours and is particularly large at mid to low latitudes. This regular variation is dependent on local time, latitude, season and solar cycle. It is caused mainly by electrical currents in the upper atmosphere (Macmillan and Droujinina, 2007). During the data selection process, only the data for 3 months out of 60 (November 2001, October 2002 and June 2003) were not considered due to insufficient geographical coverage. Linear interpolation was used to fill small gaps.

The ground data are collected from the continuous recording of geomagnetic field variations at Hermanus $\left(34^{\circ} 25.5^{\prime} \mathrm{S}, 19^{\circ} 13.5^{\prime} \mathrm{E}\right)$ and Tsumeb $\left(19^{\circ} 12.1^{\prime} \mathrm{S}\right.$, $\left.17^{\circ} 35.1^{\prime} \mathrm{E}\right)$. The primary instrument for recording of magnetic field variations is the fluxgate magnetometer model FGE, manufactured by the Danish Meteorological Institute in Copenhagen, Denmark. This instrument is based on three-axis linear-core flux-gate technology, optimised for long term stability and records the components $H, D$, and $Z$. A Geometrics Proton Precession Magnetometer instrument was used to record the total field intensity $(F)$. As mentioned previously, the investigation employed 5 year's of 1-monthly averaged data. The Tsumeb data quality was for certain intervals not acceptable and the linear interpolation was used to fill the gaps. The ground data selection was done considering only night and quiet time data as clarified in the satellite data selection.

\section{Polynomial Modelling and Results}

The derivation of annual secular variation field models for the interval 2001-2005 was done by focusing on January and December months in each year according to method (a). We chose January and December to provide a 1 year interval for SV purposes and also because external field conditions are the same for both months (summer in Southern Hemisphere). We obtained the annual secular variation field values by calculating the change between the main field polynomial models of January and December (Figs. 2, 3 and 4). Figures 5, 6 and 7 correspond to CHAOS-2 model (Olsen et al., 2006) and Fig. 8 shows the comparison of the polynomial model (PolyM) with the global field model CHAOS-2 at the two selected reference points.

In method (b), the annual secular variation at 2 selected points, and 2 permanent observatories were fitted with a 

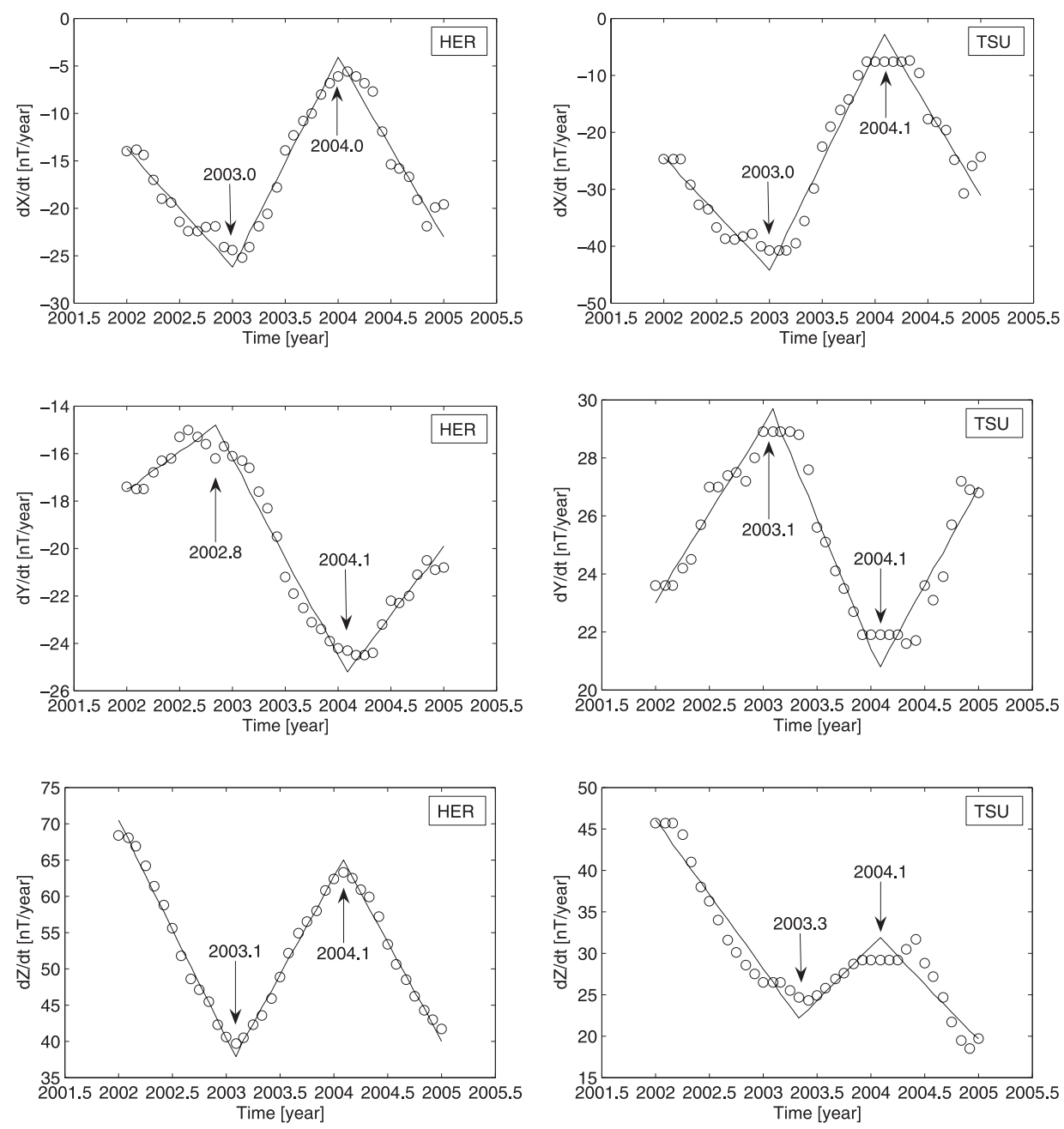

Fig. 10. The plots of the first time derivative of 3 components $(d X / d t, d Y / d t$, and $d Z / d t)$ at 2 permanent ground-based observatories (HER and TSU) for years 2001-2005. The indicated epochs of rapid SV fluctuations are associated with an error of \pm 0.1 year.

Table 3. The identified epochs of rapid SV fluctuations at 2 selected points (at $400 \mathrm{~km}$ altitude just above HER and TSU) using the polynomial monthly main field models.

\begin{tabular}{|c|c|c|c|c|c|c|}
\hline & & $\begin{array}{c}\text { Gradient } \\
\text { before } \\
{\left[\mathrm{nT} / \mathrm{yr}^{2}\right]}\end{array}$ & $\begin{array}{l}\text { Epoch of } \\
\text { rapid SV } \\
\text { fluctuation }\end{array}$ & $\begin{array}{c}\text { Gradient between } \\
\text { the epochs } \\
{\left[\mathrm{nT} / \mathrm{yr}^{2}\right]}\end{array}$ & $\begin{array}{l}\text { Epoch of } \\
\text { rapid SV } \\
\text { fluctuation }\end{array}$ & $\begin{array}{c}\text { Gradient } \\
\text { after } \\
{\left[\mathrm{nT} / \mathrm{yr}^{2}\right]}\end{array}$ \\
\hline \multirow{3}{*}{ HER } & $X$ & -5.8 & 2003.1 & 14.0 & 2004.1 & -9.9 \\
\hline & $Y$ & 2.0 & 2003.4 & -4.7 & 2004.1 & 1.2 \\
\hline & $Z$ & -12.2 & 2003.0 & 8.4 & 2004.1 & -10.4 \\
\hline \multirow{3}{*}{ TSU } & $X$ & -8.6 & 2003.1 & 18.4 & 2004.1 & -9.2 \\
\hline & $Y$ & 3.0 & 2003.2 & -4.0 & 2004.3 & 1.9 \\
\hline & $Z$ & -7.0 & 2002.9 & 3.7 & 2004.0 & -9.4 \\
\hline
\end{tabular}

best piece-wise linear fit to identify the epochs of rapid secular variation fluctuations of $X, Y$ and $Z$ components (Figs. 9 and 10). The analysis of the strength of rapid SV fluctuations was done by calculating the gradient of SV before and after the identified epoch of rapid SV fluctuation (Tables 3 and 4).

\section{Discussion and Conclusion}

A rapid SV fluctuation occurs when the secular variation experiences an abrupt change in its slope. It involves rapid variations over short timescales of only a few months
(Mandea and Olsen, 2009). The analysis of CHAMP satellite data for 2001-2005 over the southern Africa region, as illustrated in Figs. 2, 3 and 4, shows the occurrence of a rapid SV fluctuation during this period as evidenced in all geomagnetic field components. The evolution of the zero secular variation contour line of several components across southern Africa is testimony of the occurrence of a rapid SV fluctuation.

It is clearer in the $X$ component where the secular variation pattern changes from 2001.5 with the decrease in secular variation from west to east and reaches a minimum 
Table 4. The identified epochs of rapid SV fluctuations at the 2 permanent observatories (HER and TSU) using observatory data.

\begin{tabular}{|c|c|c|c|c|c|c|}
\hline & & $\begin{array}{c}\text { Gradient } \\
\text { before } \\
{\left[\mathrm{nT} / \mathrm{yr}^{2}\right]}\end{array}$ & $\begin{array}{l}\text { Epoch of } \\
\text { rapid SV } \\
\text { fluctuation }\end{array}$ & $\begin{array}{c}\text { Gradient between } \\
\text { the epochs } \\
{\left[\mathrm{nT} / \mathrm{yr}^{2}\right]}\end{array}$ & $\begin{array}{l}\text { Epoch of } \\
\text { rapid SV } \\
\text { fluctuation }\end{array}$ & $\begin{array}{c}\text { Gradient } \\
\text { after } \\
{\left[\mathrm{nT} / \mathrm{yr}^{2}\right]} \\
\end{array}$ \\
\hline \multirow{3}{*}{ HER } & $X$ & -12.5 & 2003.0 & 22.1 & 2004.0 & -18.9 \\
\hline & $Y$ & 2.7 & 2002.8 & -8.3 & 2004.1 & 5.8 \\
\hline & $Z$ & -29.9 & 2003.1 & 27.1 & 2004.1 & -27.5 \\
\hline \multirow{3}{*}{ TSU } & $X$ & -19.8 & 2003.0 & 38.0 & 2004.1 & -31.1 \\
\hline & $Y$ & 6.1 & 2003.1 & -8.9 & 2004.1 & 6.8 \\
\hline & $Z$ & -18.0 & 2003.3 & 12.8 & 2004.1 & -13.4 \\
\hline
\end{tabular}

in 2003.5 and then gradually starts increasing from east to west again before reaching approximately its original pattern in 2005.5. Figures 5, 6 and 7 show the plots of secular variation in $X, Y$ and $Z$ components derived from the CHAOS-2 model at $400 \mathrm{~km}$ over the same region of study. The two models (PolyM and CHAOS-2) show very similar patterns of geomagnetic field variation in $Y$ and $Z$ components, while the patterns of $X$ component are quite different. But, there is no clear abrupt change of secular variation shown in the CHAOS-2 model plots for any geomagnetic field component. And the values of secular variation, with the exception of $Z$ component, are slightly different. This difference can be attributed to regional models that are (i) more accurate over their regions of application than global models and (ii) also able to represent wavelengths shorter than those in global field models (Haines, 1990). The rather smooth behaviour of CHAOS-2 secular variation (Fig. 8) can also be attributed to the use of splines to parameterize the time behaviour of the geomagnetic field. The plots of secular variation as revealed at the selected points show more detailed structure in the abrupt change of secular variation than the regional contour plots and observing the evolution of different contour lines (Fig. 9). Table 3 shows that both selected reference points at $400 \mathrm{~km}$ (just above HER and TSU) support the occurrence of 2 rapid SV fluctuations in the $X, Y$ and $Z$ components around 2003.0 and 2004.0 epochs.

The analysis of the monthly time series data for the ground observatories supported these results. At 2 permanent observatories (HER and TSU) the occurrence of rapid SV fluctuations in the $X, Y$ and $Z$ components is around 2003.0 and 2004.0 epochs (Fig. 10 and Table 4). The clear difference between distribution of data between Figs. 9 and 10 demonstrates the high quality of the ground data from magnetic permanent observatories.

As shown in Figs. 2-4, the SV of 3 components over the southern Africa region indicates that $d X / d t$ increases from west to east direction $\left(1 \mathrm{nT} / 1^{\circ}\right.$ long.). For the east component, $d Y / d t$ decreases from west to east $\left(1.5 \mathrm{nT} / 1^{\circ}\right.$ long.). And the $\mathrm{SV}$ of $Z$ component, $d Z / d t$ decreases from west to east ( $1 \mathrm{nT} / 1^{\circ}$ long.), but a small west-northern part shows an increase from west to east direction $\left(1.3 \mathrm{nT} / 1^{\circ}\right.$ long.).

These results indicate that southern Africa is a region of complex and rapid SV. The present work also suggests that rapid SV changes can occur on time scales of one year or less, placing an upper limit on the electrical conductivity of the mantle (Alexandrescu et al., 1999).

Acknowledgments. The support of the CHAMP mission by the German Aerospace Center (DLR) and the Federal Ministry of Education and Research are gratefully acknowledged. We thank R. Tozzi and an anonymous referee for their constructive comments. Comments by M. Mandea on an earlier version of the manuscript contributed to improve the final paper.

\section{References}

Alexandrescu, M., D. Gilbert, J. L. LeMouël, G. Hulot, and G. Saracco, An estimate of average lower mantle conductivity by wavelet analysis of geomagnetic jerks, J. Geophys. Res., 104, 17735-17745, 1999.

Ardizone, J. and M. Herraiz, Application of the polynomial adjustment to the aeromagnetic survey of the Spanish Mainland; Requirement and shortcomings, Earth Planets Space, 52, 183-196, 2000.

Bloxham, J., S. Zatman, and M. Dumberry, The origin of geomagnetic jerks, Nature, 420, 65-68, 2002.

Courtillot, V. and J. L. LeMouël, Geomagnetic secular variation impulses, Nature, 311, 709-716, 1984.

Haines, G. V., Regional magnetic field modelling: A review, J. Geomag. Geoelectr., 42, 1001-1018, 1990.

Korte, M., M. Mandea, P. B. Kotzé, E. Nahayo, and B. Pretorius, Improved observations at the southern African geomagnetic repeat station network, S. Afr. J. Geol., 110, 175-186, 2007.

Kotzé, P. B., Spherical cap modelling of Ørsted magnetic field vectors over southern Africa, Earth Planets Space, 53, 357-361, 2001.

Lühr, H., Announcement of opportunity for CHAMP, GeoForschungsZentrum, Potsdam, Germany, 2001.

Macmillan, S. and A. Droujinina, Long-term trends in geomagnetic daily variation, Earth Planets Space, 59(3), 791-395, 2007.

Malin, S. R. C. and B. M. Hodder, Was the 1970 geomagnetic jerk of internal or external origin?, Nature, 296, 726-728, 1982.

Mandea, M. and N. Olsen, Geomagnetic and archeomagnetic jerks: Where do we stand?, Eos Trans. AGU, 90(24), 208-208, 2009.

Mandea, M., E. Bellanger, and J. L. LeMouël, A geomagnetic jerk for the end of the 20th century?, Earth Planet. Sci. Lett., 183, 369-373, 2000.

Maus, S., S. McLean, D. Dater, H. Lühr, M. Rother, W. Mai, and S. Choi, NGDC/GFZ candidate models for the 10th generation International Geomagnetic Reference Field, Earth Planets Space, 57, 1151-1156, 2005.

Olsen, N. and M. Mandea, Investigation of a secular variation impulse using satellite data: The 2003 geomagnetic jerk, Earth Planet. Sci. Lett., 255, 94-105, 2007.

Olsen, N. and M. Mandea, Rapidly changing flows in the Earth's core, Nature Geosci., 1, 390-394, 2008.

Olsen, N., H. Lühr, T. J. Sabaka, M. Mandea, M. Rother, L. TøffnerClousen, and S. Choi, CHAOS-A model of Earth's magnetic field derived from CHAMP, Ørsted, and SAC-C magnetic satellite data, Geophys. J. Int., 166, 67-75, 2006.

Pochtarev, V. I., Normal magnetic field of the Earth, Nauka, Moscow, 232, 1984.

Shu, Y., C. An, P. Golovkov, N. M. Rotanova, and T. N. Bondar, Analysis of geomagnetic secular variations in eastern Asia during the last 30 years, Geomagn. Aeron., 35, 871-875, 1996.

E. Nahayo (e-mail: enahayo@sansa.org.za) and P. B. Kotzé 